\title{
Estimating the Benefits of a Faith-Based Correctional Program
}

\author{
Grant Duwe ${ }^{1, *}$ and Byron R. Johnson ${ }^{2}$ \\ ${ }^{1}$ Minnesota Department of Corrections, St. Paul, MN, USA \\ ${ }^{2}$ Institute for Studies of Religion, Baylor University, Waco, TX, USA
}

\begin{abstract}
A recent outcome evaluation of the InnerChange Freedom Initiative (InnerChange), a faith-based prisoner reentry program that has operated within Minnesota's prison system since 2002, showed the program is effective in lowering recidivism. This study extends research on InnerChange by conducting a cost-benefit analysis of the program. Because InnerChange relies heavily on volunteers and program costs are privately funded, the program exacts no additional costs to the State of Minnesota. As a result, this study focused on estimating the program's benefits by examining recidivism and post-release employment. The findings showed that during its first six years of operation in Minnesota, InnerChange produced an estimated benefit of $\$ 3$ million, which amounts to nearly $\$ 8,300$ per participant. Much of this benefit stems from costs avoided as a result of the program's impact on reoffending.
\end{abstract}

Keywords: Prisoner reentry, recidivism, employment, religion, cost-benefit analysis.

\section{INTRODUCTION}

It is not a new idea that the life of even the worst offender can be transformed. Religious adherents and faith-based practitioners have long proclaimed this message. Some of the earliest prisons in America were also based on the belief that crime was a moral and spiritual problem, and that prisoners needed religion to reform. Consequently, intensive religious instruction and training was integral in some of America's earliest correctional facilities (Morris and Rothman, 1998). It should not come as a surprise, then, that a significant percentage of today's prison vernacular as well as philosophy draw from religious concepts or perspectives (e.g., corrections, penitentiary, solitary confinement, reform, and restorative justice).

\section{Faith-Based Interventions and Offender \\ Rehabilitation}

One of the rationales for the emphasis on faithbased prison interventions is the common criticism that traditional prison programs are simply not effective in rehabilitating inmates or helping former prisoners become law-abiding citizens once they are released back into society. Many prison wardens and correctional administrators would likely agree with this assessment. This observation is not meant to suggest prison officials are opposed to the idea of rehabilitation. Rather, it is more a recognition of the illusive nature of authentic rehabilitation, especially considering the finite resources available for correctional programs.

The question of whether secular treatment programs are effective was addressed in Robert

*Address correspondence to this author at the Minnesota Department of Corrections, 1450 Energy Park Drive, Suite 200, St. Paul, MN55108-5219, USA; Tel: (651) 361-7377; Fax:(651) 642-0223; E-mail: grant.duwe@state.mn.us
Martinson's widely cited study, "What Works? Questions and Answers about Prison Reform" (1974). This study, or at least many of the subsequent interpretations of it, seemed to answer this question in the negative - nothing works. However, subsequent research has more accurately answered the question this way - some programs do reduce recidivism for some offenders, in some settings (Sherman, Gottfredson, MacKenzie, Eck, Reuter, and Bushway, 1997). Over the last two decades there have been a number of studies systematically evaluating the effectiveness of various correctional treatment programs to reduce recidivism and have very similar conclusions about what is effective in reducing recidivism following release from prison (Aos, Phipps, Barnoski, and Lieb, 2001; Cullen, 2002; Gaes, Flanagan, Motiuk, and Stewart, 1999; Lawrence, Mears, Dublin, and Travis, 2002; and MacKenzie and Hickman, 1998). The rehabilitation programs that were most effective included at least one of the following components: 1) academic skills training (e.g. adult basic education), 2) vocational skills training (e.g. acquiring and maintaining employment), 3) cognitive skills programs (e.g. goal-setting, problem-solving, and self-control), and 4) drug abuse treatment.

\section{Prison Ministry and Recidivism Reduction}

Prison Fellowship has the most pervasive outreach of existing prison ministries. ${ }^{1}$ At the core of Prison

\footnotetext{
${ }^{1} \mathrm{PF}$ is the largest organized prison ministry in the United States. According to Prison Fellowship's most recent Annual Report, the ministry is supported by the efforts of over 300,000 volunteers. Some 200,000 prisoners per month, participate in either Bible studies or seminars led by PF-trained volunteers in over 1,300 of the country's 1,850 state and federal correctional facilities (see God at Work in Prison Fellowship: Annual Report Fiscal Year 2001-2002, Prison Fellowship Ministries, 44180 Riverside Parkway, Lansdowne, VA 20176 (www.prisonfellowship.org).
} 
Fellowship's (PF) mission is the premise that crime is fundamentally a moral and spiritual problem requiring a moral and spiritual solution. ${ }^{2}$ Prison Fellowship and many other prison ministries still believe religion is the critical ingredient in offender rehabilitation and helping former prisoners to lead a crime-free life. PF offers prisoners a variety of in-prison programs. Through oneto-three-day seminars and weekly Bible studies, inmates are taught to set goals that prepare them for release. These programs teach concepts such as "surviving the prison environment, beginning a relationship with God in prison, overcoming obstacles, building better families, sharing the Gospel behind bars, and preparing for life on the outside." Weekly Bible studies usually last an hour, and one-to-three day seminars might be offered several times a year at a particular prison. The level of prisoner exposure to such religious programs would probably be a maximum of 50 hours of Bible study and several days of intensive seminars annually - a relatively modest correctional intervention.

There is, however, some preliminary empirical evidence that regular participation in volunteer-led Bible studies is associated with reductions in recidivism (Johnson, Larson, and Pitts, 1997). For example, Johnson, et al, found that prisoners from four different New York prisons who attended 10 or more Bible studies during a one-year period prior to release were significantly less likely to be arrested during a one-year post-release follow-up study. In a more recent study tracking these same prisoners for an additional seven years, Johnson found that regular participation in volunteer-led Bible studies remains significantly linked to lower rates of recidivism for two years and even three years post-release (2004). Even for a substantial intervention it is noteworthy to observe an effect two or three-years after release, but for a minor intervention like volunteer-led Bible studies, it is unheard of.

If participation in relatively small doses of religious programs can have a measurable and beneficial effect on inmates, imagine the effect of an extended faithbased prison program might have? Believing a much more intensive intervention could lead to even better outcomes, PF began to strategize how it might be possible to create an unapologetically faith-based community within prisons in the early 1990s.

\footnotetext{
${ }^{2}$ Prison Fellowship identifies itself as a not-for-profit, volunteer-reliant ministry whose mission is to "exhort, equip, and assist the Church in its ministry to prisoners, ex-prisoners, victims, and their families, and to promote biblical standards of justice in the criminal justice system."
}

In recent years, in fact, there has been growing interest in moving beyond traditional prison ministry that has tended to focus primarily on preaching to prisoners. Faith-motivated volunteers have greatly expanded their outreach efforts over the last several decades and have developed structured programs that are multifaceted. Indeed, it is not uncommon for a prison to have to significant numbers of prisoners participating in formalized faith-based prison programs, or faith-based dorms. Moreover, several prisons in the United States could now be classified as faith-based. Add to this trend another new and non-significant faithbased development - the addition of seminaries housed within the prison itself. ${ }^{3}$

\section{LITERATURE REVIEW}

One might be surprised to learn an extensive and well-developed research literature addressing the relationship of religion to crime does not exist. This is unfortunate, since properly understanding the intricacies of the relationship between religion and crime may hold considerable potential for operating a more efficacious criminal justice system. Further, a more developed literature may provide valuable feedback and ongoing assistance to secular and sacred groups in implementing programs and providing vibrant networks of support in order to more effectively reduce crime and delinquency. Understanding how religion might prevent crime or help youth from disadvantaged neighborhoods to be resilient in spite of their surroundings represent several of many possible and policy relevant areas in need of thoughtful study. Because faith-based programs focusing on mentoring, drug treatment, restorative justice, cognitive restructuring, or spiritual transformation already exist in most communities, rigorous evaluation and ongoing research will make it possible to not only understand how faith might matter, but how these faith-informed approaches can be modified and improved. In order for this to happen there must be sufficient interest in independent research from officials within the criminal justice system. Additionally, faith-motivated volunteers and organizations must also be open to the notion that objective research is something they should consider; if no other reason but that it is an act of stewardship. Research like this will make it possible to improve programs in order to achieve better and more effective outcomes.

${ }^{3}$ Prison seminaries have recently been implemented in Louisiana, Texas, and California. 
Contemporary research on the relationship between religion and crime is generally traced to Travis Hirschi and Rodney Starks's important study entitled "Hellfire and Delinquency," (Hirschi and Stark, 1969). The study generated a great deal of interest among academics and beyond because it provided evidence that religion held little or no influence over the behavior of youth was greeted with positive and negative reactions. A number of scholars replicated the study and the replications both supported (Burkett and White, 1974) and refuted (Albrecht and Alcorn, 1977; Higgins and Albrecht, 1977) Hirschi and Stark's original finding. After a series of studies over a decade or so, rather than clarifying the situation, we were still not able to answer the question of whether religion helped reduce delinquency. Stark and colleagues would later return to the issue and suggested that these contradictory findings were likely the result of the moral makeup of the community being studied. That is to say, areas with high church membership and attendance rates represented "moral communities," while areas with low church membership were more "secularized communities" (Stark, Kent, and Doyle, 1982). Stark predicted religion would deter delinquency in moral communities, but there would be little or no effect of religiosity on individuals residing in secularized communities.

The "moral communities" hypothesis provided an important theoretical framework for understanding why religion reduced delinquency in some studies, while other studies found religion had no significant impact on delinquency (Stark, 1996; Stark, Kent, and Doyle, 1982). Over the last decades scholars have continued approaching the religion-crime relationship from a number of different perspectives and have helped us to better understand the nature of the relationship between religion and crime.

One of the first studies to shed new light on the religion-crime relationship was conducted not by a criminologist, but by an economist, Richard Freeman, at Harvard University. Freeman was writing a book on the employment crisis among young, black males raised in poverty in urban America. Analyzing data collected by the National Bureau of Economic Research (NBER) on black, male youth living in poverty tracts in Philadelphia, Boston, and Chicago, Freeman found church attending youth were significantly less likely to engage in a series of illegal behaviors than youth who did not attend church (Freeman, 1986). Additionally, Freeman found that frequent church attendance was also associated with improved academic performance as well as positive employment indicators. Freeman's study is particularly helpful in turning our attention to one of the factors helping at-risk youth become "resilient youth" - kids who stay out of trouble in spite of the bad neighborhoods in which they reside.

More than a decade later, Johnson and colleagues would replicate Freeman's 1986 study and found strong empirical support for his conclusions (Johnson, Larson, Li, and Jang, 2000). Results showed that the frequency of attending religious services significantly lowered the likelihood that young black males living in poverty would commit illegal activities, use drugs, or be involved in drug selling (Johnson and Siegel, 2008). Johnson and colleagues found that youth from singleparent households were similarly protected by frequent church attendance. Johnson, Jang, Li, and Larson (2000) found in another study that active participation in a church appears to play a critical protective role in fostering social control as well as making youth resilient to the negative influences of living in disadvantaged environments.

There is also mounting evidence that religious involvement may lower the risks of a broad range of delinquent behaviors, including both minor and serious forms of criminal behavior (Evans, Cullen, Burton, Dunaway, Payne, and Kethineni, 1996). Aided by several systematic reviews of this literature, it has become increasingly clear the research literature is not ambiguous. In a systematic review of 40 studies focusing on the relationship between religion and delinquency, it was found that most of these studies reported an inverse relationship between measures of religiosity and delinquency (i.e. increasing religiosity is related to decreasing delinquency (Johnson, Li, McCullough, and Larson, 2000). Several studies found no relationship or reported mixed findings, and only one found a positive link between greater religiosity and increasing delinquency (i.e. increasing religiosity is associated with increasing delinquency). Moreover, Johnson et al., found that among those studies with the most sophisticated research designs, there was an increased likelihood that higher levels of religiosity were linked to decreases in delinquency.

In another systematic review, Baier and Wright (2001) review 60 studies within the religiositydelinquency literature and reach much the same conclusion as the previous study by Johnson et al. They find that studies using larger and more representative datasets are more likely to find 
significant inverse effects (i.e., increasing religiosity and decreasing delinquency) than studies that utilize smaller, regional, or convenient samples. In a third systematic review, Johnson, Tompkins, and Webb (2002) reviewed studies examining religion and multiple outcome areas including several that are relevant for our current discussion (i.e. alcohol abuse, drug use/abuse, and crime/delinquency). Among the 97 alcohol studies reviewed, only two studies found religiosity to be associated with deleterious outcomes. Another ten studies reported inconclusive findings, while 85 studies found an inverse relationship; indicating increasing religiosity was associated with a lowered likelihood of alcohol abuse. Johnson also found a similar pattern among the 54 studies reviewed examining drug use or abuse. Fifty of the 54 studies found increasing religiousness linked to decreasing drug use or abuse, while only one study found a positive relationship. Finally, Johnson reviewed another 46 studies within the crime and delinquency literature that examine the influence of religion and the same trend is obvious - increasing religiosity is associated with lowered likelihood of criminal or delinquent behavior (37 studies), while religiosity is positively related to delinquency in only one study.

In sum, these reviews confirm consistent and mounting evidence suggesting increasing religious commitment or involvement helps individuals avoid crime and delinquency. But are these research findings consistent with the more recent research literature on religion and crime? In order to answer this question, Johnson and Jang (2010) report findings from the most thorough systematic review conducted to date of the relevant research literature on religion and crime. This comprehensive review utilized multiple research strategies to locate studies from diverse disciplines and varied methodological perspectives. All total this review located 273 studies on religion and crime that were published between 1944 and 2010, making the current systematic review the most extensive to be undertaken on this topic. In this systematic review, Johnson and Jang examined the type of study (e.g. cross sectional, prospective cohort, retrospective, experimental, case control, or descriptive), the sampling method (e.g. random, probability, systematic sampling, convenience/purposive sample), the number of subjects in the sample, population (e.g. children, adolescents, high school students, college students, or adults), location, religious variables included in the analysis (e.g. religious attendance, scripture study, subjective religiosity, religious commitment, intrinsic religiosity, extrinsic religiosity, etc.), controls, and findings (e.g. no association, mixed evidence, beneficial association with outcome, or harmful association with outcome).

Consistent with previous systematic reviews, Johnson and Jang concluded the vast majority of these studies find religion and religious involvement to be associated with decreases in various measures of crime and delinquency. Specifically, they found 90 percent of the studies (247 of 273) report an inverse or beneficial relationship between religion and some measure of crime or delinquency. Only 9 percent of the studies (24 of 273) found no association or reported mixed findings, whereas only two out of 273 studies report religion was associated with a harmful outcome.

Until recently there has been a lack of consensus about the nature of this relationship between religion and crime. Based on our exhaustive review of studies utilizing vastly different methods, samples, and research designs, increasing religiosity is consistently linked with decreases in various measures of crime or delinquency. As expected, these findings are particularly pronounced among the more methodologically and statistically sophisticated studies, especially those relying upon nationally representative samples. Put simply, increasing religiousness has found to be associated with decreases in crime or delinquency.

\section{The InnerChange Program}

First implemented in the United States in Texas in 1997, InnerChange is a voluntary correctional program developed by Prison Fellowship (PF) Ministries. InnerChange attempts to help inmates prepare for reentry through educational, values-based programming that connects spiritual development with educational, vocational and life skills training (Johnson and Larson, 2003). InnerChange also strives to build social support for participants by not only involving local faith communities in religious events and activities, but also by matching each participant with a mentor while still incarcerated. InnerChange programming is based on the values reflected in the life and teaching of Jesus Christ, although inmates do not have to be Christian to participate in the program. Currently, there are eight InnerChange programs, three of which are for female inmates, operating in Arkansas, Kansas, Minnesota, Missouri, and Texas.

\section{Texas InnerChange Evaluation}

In 2003, Johnson and Larson evaluated the InnerChange program that had been operating at a 
state correctional facility in Texas since 1997. In their evaluation, Johnson and Larson (2003) found that the program did not significantly reduce recidivism for all offenders who entered the program. Rather, only offenders who graduated from the program had lower recidivism rates. In response to the findings from this evaluation, all InnerChange programs moved toward a standardized curriculum. Moreover, InnerChange made a substantial change to its curriculum in 2004 by incorporating recommendations emanating from the evidence-based practices movement, most notably the suggestions made by Cullen and Gendreau (2000) regarding the characteristics of effective correctional programs. As a result, InnerChange began to augment some of the biblical instruction with values-based programming that specifically addressed the criminogenic needs of participants. Current InnerChange programming covers areas relating to substance abuse education, victim impact awareness, life-skills development, cognitive skill development, educational attainment, community reentry, religious instruction, and moral development.

\section{Description of the InnerChange Program in Minnesota}

In Minnesota, the first male inmates entered the InnerChange program at the Minnesota Correctional Facility (MCF)-Lino Lakes, a medium-security prison, during the summer of 2002. Similar to programs operated in other states, InnerChange programming and staffing costs are privately funded. Still, the program depends heavily on volunteers from local churches and religious organizations for the delivery of many of the services provided. As is the case with inmates in general, the responsibilities relating to the security, housing, employment, and cost of other services provided to InnerChange participants are borne by the Minnesota Department of Corrections (MnDOC).

Inmates proceed through the Minnesota program in a cohort comprised of roughly 40 men and begin participating 18-24 months prior to their release from prison. As a result, the main eligibility criterion to participate in InnerChange is having a length of stay in prison no less than 18 months. Similar to a therapeutic community, participants live together in the same housing unit during the two highly structured, in-prison phases of the program. Phase 1, which lasts for the first twelve months, includes three hours of instruction each weekday morning followed by work or compulsory educational programming in the afternoon and additional programming in the evening.

The curriculum for the first phase, delivered primarily during the morning instruction period by InnerChange counselors, is divided into four quarters. The first quarter introduces participants to the core values upon which InnerChange is based. In addition, the program teaches cognitive skills based on Truthought material developed by Stanton Samenow as well as "A New Direction" curriculum collaboratively developed by the Hazelden Foundation and MnDOC chemical dependency program staff. Quarters two and three introduce reentry and addiction issues while covering a host of topics that encourage participants to accept responsibility for their criminal behavior. The fourth quarter focuses on chemical dependency education and relapse prevention.

Phase 2 lasts for a minimum of six months, and much of the offender's time is spent working within the facility during the day and attending classes during the evening. During this time, offenders also have the opportunity to be matched with a mentor from the community. For those who accept this option, they meet with their assigned mentor on a weekly basis throughout the second phase. Each offender also works with InnerChange counselors to establish reentry goals.

Throughout the in-prison phases, offenders participate in evening programming approximately four nights each week. All evening programming is provided by screened and trained volunteers from local churches and religious organizations. Activities vary considerably, ranging from small group Bible study to discussion of life skills topics. Churches and other community organizations provide special programs on Friday nights, which are open to all inmates within the prison. The intent of the evening programming is to provide additional opportunities that allow InnerChange participants to build ties to the community and acquire valuable socialization skills.

Phase 2 culminates in the release of the inmate from prison, typically on supervised release or through the MnDOC's work release program. A small number of InnerChange inmates enter the Challenge Incarceration Program (CIP), the MnDOC's boot camp. The third and final phase of InnerChange begins at release, and is the 12-month, reentry phase of the program. During the reentry phase, mentors and the InnerChange reentry team work with participants to 
build pro-social relationships within the community by providing them with support groups, peer mentoring, one-on-one counseling, and interaction with volunteers. These relationships create opportunities for offenders to interact with individuals who are successfully involved in their communities, families, and social circles. The program also attempts to address housing and employment issues by developing relationships with employers, housing providers, and other reentry service providers.

\section{Minnesota InnerChange Evaluation}

Using a rigorous, retrospective quasi-experimental design, Duwe and King (2013) evaluated the effectiveness of the InnerChange program in Minnesota by comparing recidivism outcomes among 366 InnerChange participants and a matched comparison group of 366 non-participants who were released from Minnesota prisons between August 2003 and December 2009. To fully capture the program's impact on recidivism, Duwe and King (2013) used four separate measures-rearrest, reconviction, reincarceration for a new felony, and revocation for a technical violation. In addition, Duwe and King (2013) examined 27 covariates that included measures relating to demographics (age at release and race/ethnicity), criminal history, recidivism risk (Level of Service Inventory-Revised score), religious affiliation, offense type, prison misconduct, participation in prison programming, and type of post-release supervision. Therefore, Duwe and King (2013) not only controlled for factors known to increase recidivism risk, but also for those that have been shown to mitigate risk among Minnesota prisoners, such as chemical dependency treatment (Duwe, 2010), sex offender treatment (Duwe and Goldman, 2009), and participation in the Challenge Incarceration Program-the state's correctional boot camp (Duwe and Kerschner, 2008).

Duwe and King (2013) controlled for observable selection bias by using propensity score matching. The results from the propensity score analyses showed there were a number of factors that predicted whether offenders entered InnerChange. White offenders, younger offenders, inmates who reported a Christian affiliation (e.g., Catholic, Baptist, Lutheran, and Other Christian), drug offenders, and offenders with longer lengths of stay in prison had significantly greater odds of entering InnerChange. In contrast, offenders admitted to prison as probation violators, sex offenders, and those with more discipline convictions were significantly less likely to enter InnerChange. At the time of release from prison, InnerChange participants were significantly more likely to be placed on work release and significantly less likely to participate in a correctional boot camp. Because program enrollment increased during the time period covered in this evaluation, release year was positively associated with entering InnerChange.

Due to the use of propensity score matching, there were no statistically significant differences between offenders in the InnerChange and comparison groups among the 27 control variables included in the analyses. Given that these covariates were significantly associated with the probability of entering InnerChange and/or recidivism risk, the comparison group provided a rigorous counterfactual estimate of what would have happened to the InnerChange offenders had they not participated in the program. Using Cox regression, Duwe and King (2013) found that InnerChange significantly reduced the three recidivism measures relating to reoffending but did not have a significant impact on technical violation revocations. More specifically, participation in InnerChange lowered the hazard of recidivism by 26 percent for rearrest, 35 percent for reconviction, and 40 percent for new offense reincarceration.

Duwe and King (2013) reported that the best recidivism outcomes were observed for the InnerChange participants who received a continuum of mentoring support from the institution to the community. They also found, however, that minority offenders were significantly less likely to enter InnerChange and did significantly worse for at least one measure of recidivism (new offense reincarceration), which may have been due to the fact that these offenders were significantly less likely to have a continuum of mentoring support.

In explaining why the InnerChange program in Minnesota is successful in reducing recidivism, Duwe and King (2013) noted that traditional or mainstream Christian doctrine promotes a pro-social, crime-free lifestyle, which is consistent with the negative religiosity-crime relationship generally reported in the literature (Baier and Wright, 2001; Johnson, De Li, Larson, and McCullough, 2000). But Duwe and King (2013) also pointed out that the InnerChange program shares a number of similarities with correctional programs that have been proven to be effective. First, since 2004, the InnerChange program has addressed the criminogenic needs of participants by introducing programming that focuses on issues such as 
education, criminal thinking, and chemical dependency. Second, similar to a therapeutic community, offenders participating in InnerChange live in one housing unit that is separated from the general prison population. Third, InnerChange participants receive a "continuum of care" insofar as the program lasts for at least 18 months in the institution and then for the first 12 months following release when offenders are supported by a mentor and a faith community. Finally, by providing participants with mentors and connecting them with faith communities after their release from prison, InnerChange expands the social support networks for offenders both during and after their confinement.

\section{DATA AND METHODOLOGY}

This study conducts a cost-benefit analysis of the InnerChange program in Minnesota from its inception in 2002 through the end of 2009. Identifying the costs and benefits is paramount in any cost-benefit analysis of a correctional program. With InnerChange, however, program costs are privately funded so it exacts no additional costs to the State of Minnesota. The potential benefits include, first and foremost, a reduction in recidivism. Decreased recidivism can produce a benefit by lowering victimization costs and reducing the use of law enforcement, courts, and corrections resources.

Although InnerChange was not specifically designed to help offenders find jobs following their release from prison, the increased social support participants receive may produce salutary effects for employment. While social ties are important for anyone seeking a job (Granovetter, 1983), they may be especially salient for released prisoners. A criminal history can make an individual appear untrustworthy and, therefore, less employable (Pager, 2003; Petersilia, 2003; Western et al. 2001). An endorsement by a friend or family member can persuade potential employers to overlook the stigma of incarceration. For example, Berg and Huebner (2011) found that released prisoners who had strong family ties were more likely to maintain a job compared to less attached prisoners. Moreover, released prisoners who had jobs and strong family ties were much less likely to reoffend. When offenders gain employment, they pay taxes to the state, which is a quantifiable benefit. InnerChange may also generate other benefits, but recidivism and employment are the two potential benefits we will focus on for this study.

\section{Recidivism}

To determine whether InnerChange has produced a benefit resulting from reduced recidivism, we analyze the recidivism data Duwe and King (2013) collected for their evaluation. As noted above, Duwe and King (2013) used four separate recidivism measures in their study. In addition, they gathered the recidivism data through December 31, 2010. The average follow-up time for all 732 offenders was 38 months, with a minimum of one year and a maximum of more than seven years. Duwe and King (2013) obtained recidivism data on arrests and convictions from the Minnesota Bureau of Criminal Apprehension and reincarceration and revocation data from the Correctional Operations Management System (COMS) database maintained by the MnDOC. As Duwe and King (2013) pointed out, the main limitation with using these data is that they measure only arrests, convictions or incarcerations that took place in Minnesota.

In this study, we monetize the costs of recidivism in two ways. First, we calculate the costs of new criminal offenses committed by offenders in the InnerChange and comparison groups following their release from prison. The costs of individual offenses are monetized based on cost of crime estimates developed in several recent studies. Second, because the cost of crime literature has not developed estimates for technical violation revocations, we use per diem data from the $\mathrm{MnDOC}$ to calculate the costs for this type of recidivism event.

Research on the cost of crime has estimated costs of individual offenses to society based on victim costs, criminal justice costs (including police, courts, and prisons), and lost productivity of incarcerated offenders. The studies by Cohen and Piquero (2009), McCollister et al., (2010), and DeLisi et al. (2010) are three recent efforts to monetize the costs of individual offenses to society. As shown in Table 1, all three studies have developed estimates for murder, rape/sex offenses, aggravated assault, armed robbery and burglary. The Cohen and Piquero (2009) and McCollister et al. (2010) studies each developed estimates for simple robbery, arson, motor vehicle theft, fraud and theft. We use the average cost for offenses, adjusted for inflation to 2010 dollars, where more than one estimate has been developed. For offenses, however, where only one estimate has been reported, we use the cost information from a single study. For example, for cost estimates associated with stolen property, 
Table 1: Reoffense Cost Estimates, 2010 Dollars

\begin{tabular}{|c|c|c|c|c|}
\hline Rearrest Offenses & Cohen and Piquero (2009) & McCollister et al. (2010) & DeLisi et al. (2010) & Average \\
\hline Murder & $\$ 11.8$ million & $\$ 9.10$ million & $\$ 17.25$ million & $\$ 12.72$ million \\
\hline Rape/Sex Offense & $\$ 304,985$ & $\$ 243,855$ & $\$ 454,267$ & $\$ 334,369$ \\
\hline Aggravated Assault & $\$ 89,392$ & $\$ 108,388$ & $\$ 147,238$ & $\$ 115,006$ \\
\hline Simple Assault & $\$ 19,982$ & & & $\$ 19,982$ \\
\hline Armed Robbery & $\$ 294,468$ & & $\$ 340,026$ & $\$ 317,247$ \\
\hline Simple Robbery & $\$ 41,015$ & $\$ 42,851$ & & $\$ 41,933$ \\
\hline Burglary & $\$ 36,809$ & $\$ 6,545$ & $\$ 41,816$ & $\$ 28,390$ \\
\hline Arson & $\$ 120,942$ & $\$ 21,373$ & & $\$ 71,158$ \\
\hline Motor Vehicle Theft & $\$ 17,878$ & $\$ 10,910$ & & $\$ 14,394$ \\
\hline Stolen Property & & $\$ 7,974$ & & $\$ 8,076$ \\
\hline Embezzlement & & $\$ 5,550$ & & $\$ 5,550$ \\
\hline Forgery & & $\$ 5,332$ & & $\$ 5,332$ \\
\hline Fraud & $\$ 5,784$ & $\$ 5,096$ & & $\$ 5,440$ \\
\hline Theft & $\$ 4,207$ & $\$ 3,577$ & & $\$ 3,892$ \\
\hline Other (e.g., drugs) & $\$ 1,052$ & & & $\$ 1,052$ \\
\hline
\end{tabular}

embezzlement, and forgery, we rely on the estimates developed by McCollister et al. (2010). Similarly, for "other" offenses, such as drugs, which do not fall into any of these categories, we use the estimate reported by Cohen and Piquero (2009).

To determine the extent to which offenders in the InnerChange and comparison groups reoffended through the end of 2010, we counted the total number of criminal offenses for which they were convicted. We used reconviction to quantify reoffending because it provides a middle-of-the-road measure that is neither too generous nor overly conservative in estimating reoffending costs. Although rearrest is the most sensitive official measure for reoffending, it will include instances where the offender was not convicted because charges were dropped due to insufficient or exculpatory evidence. On the other hand, reincarceration for a new felony-level offense provides what is, for purposes of the cost-benefit analysis, an overly conservative measure of reoffending. For example, this measure does not include felony-level convictions in which the offender was not sentenced to prison or lower-level convictions (misdemeanor or gross misdemeanor).

To estimate the costs associated with reincarcerations resulting from technical violation revocations, we used data obtained from the MnDOC's COMS database. More specifically, InnerChange participants were compared with offenders in the comparison group on the basis of how many days they were incarcerated for a technical violation revocation following their release from prison. The overall difference (in days) between the two groups was then monetized based on the MnDOC's marginal per diem. Due to the size of the program, the number of bed days saved from a reincarceration reduction would not likely be large enough to prevent the construction of a new correctional facility. As such, marginal costs, which include only the costs to clothe and feed offenders, will be used rather than fixed costs, which also include the cost of new prison construction (Duwe and Kerschner, 2008).

\section{Employment}

To examine whether InnerChange participants contributed more money to state income tax revenue than comparison group members, data on post-release employment were obtained from the Minnesota Department of Employee and Economic Development (DEED). Similar to the recidivism data, we collected DEED data on the 732 offenders in the InnerChange and comparison groups from the time of their release from prison through the end of 2010. The main caveat with using DEED data is that it does not capture any labor (or compensation for that labor) not reported to DEED, which can occur in situations where employees are paid "under the table" for their labor. Still, the DEED 
data provide important information not only on whether offenders obtained employment, but also on how much they worked and the extent to which they were compensated. Because the employment data are compiled on a quarterly basis, information was not available on the specific date(s) when offenders entered and/or exited a job. As a result, the postrelease employment measures included: 1) any employment (dichotomized as " 1 " for employment and " 0 " for no employment), 2) total number of hours worked, 3) total wages earned, and 4) hourly wage.

Although it was beyond the scope of this study to obtain actual tax records to determine the percentage of these funds that were contributed to municipal and state tax bases each year, an estimate was calculated using the State of Minnesota's Individual Income Tax Tables for the years 2004-2010. Average annual salaries were obtained for offenders in the InnerChange and comparison groups to determine the appropriate tax rate. The difference in yearly earnings between the two groups was then multiplied by the tax rate to estimate the contribution. A few limitations should be noted, however, with this approach. First, it is likely that offenders claimed deductions and, as a result, paid less than the estimate provided in this study. Second, actual incomes may have varied from year to year, placing offenders into a higher or lower tax bracket within a given year.

\section{RESULTS}

The recidivism results, which are shown in Table 2 , indicate that InnerChange participants had lower rates than the offenders in the comparison group for all four measures. As noted earlier, the hazard ratio for the three measures pertaining strictly to reoffending (rearrest, reconviction, and reincarceration for a felony) were significantly lower for InnerChange participants. Although InnerChange participants had a lower rate of reincarcerations for a technical violation revocation (33\% vs. $36 \%)$, this difference was not statistically significant.

The post-release employment results showed that 81 percent of the InnerChange participants obtained employment following their release from prison compared to 67 percent in the comparison group. InnerChange participants worked a total of 747,184 hours during the follow-up period (an average of 2,041 per offender) compared to 583,378 for the comparison group (an average of 1,594 per offender). At a little more than $\$ 13 /$ hour, the hourly wage for InnerChange participants was nearly $\$ 1.50$ higher compared to offenders in the comparison group $(\$ 11.61)$. Overall, InnerChange participants earned nearly $\$ 11.7$ million during the follow-up period, which is approximately \$3.7 million more than what the comparison group members earned collectively. Among all employed offenders, the average annual wage was $\$ 12,181$.

In Table 3, we present the crime cost estimate results from the reoffense comparison. The results show that InnerChange participants were convicted of 134 offenses during the follow-up period compared to 260 for offenders in the comparison group. When InnerChange participants were reconvicted, however, it was generally for a more serious offense. Indeed, the average cost estimate per conviction was roughly

Table 2: Recidivism and Employment by InnerChange Participation and Outcome

\begin{tabular}{|c|c|c|}
\hline Outcomes & Comparison & InnerChange \\
\hline \multicolumn{3}{|l|}{ Recidivism } \\
\hline Rearrest & $51 \%$ & $42 \%$ \\
\hline Reconviction & $34 \%$ & $25 \%$ \\
\hline Reincarceration & $13 \%$ & $9 \%$ \\
\hline Revocation & $36 \%$ & $33 \%$ \\
\hline \multicolumn{3}{|l|}{ Post-Release Employment } \\
\hline Employment & $67 \%$ & $81 \%$ \\
\hline Total Hours & 583,378 & 747,184 \\
\hline Average per offender & 1,594 & 2,041 \\
\hline Total Wages & $\$ 7,987,888$ & $\$ 11,708,937$ \\
\hline Average per offender & $\$ 21,825$ & $\$ 31,992$ \\
\hline Hourly Wage & $\$ 11.61$ & $\$ 13.03$ \\
\hline $\mathrm{N}$ & 366 & 366 \\
\hline
\end{tabular}


Table 3: Estimated Reoffense Cost Comparison Between InnerChange and Comparison Groups*

\begin{tabular}{|c|c|c|c|}
\hline Reconviction Offenses & $\begin{array}{c}\text { Estimated Cost Per } \\
\text { Offense }\end{array}$ & InnerChange & Comparison \\
\hline & & Reconvictions (Total Cost) & Reconvictions (Total Cost) \\
\hline Homicide & $\$ 12.7$ million & 1 (\$12.7 million) & 1 (\$12.7 million) \\
\hline Armed Robbery & $\$ 317,247$ & $1(\$ 317,247)$ & 6 (\$1.90 million) \\
\hline Aggravated Assault & $\$ 115,006$ & $4(\$ 449,864)$ & $3(\$ 337,398)$ \\
\hline Simple Robbery & $\$ 41,933$ & $1(\$ 41,933)$ & $2(\$ 83,866)$ \\
\hline Burglary & $\$ 28,390$ & $6(\$ 170,338)$ & $30(\$ 851,691)$ \\
\hline Simple Assault & $\$ 19,982$ & $37(\$ 739,326)$ & 63 (\$1.3 million) \\
\hline Motor Vehicle Theft & $\$ 14,394$ & $2(\$ 28,788)$ & $9(\$ 129,547)$ \\
\hline Stolen Property & $\$ 8,076$ & $0(\$ 0)$ & $3(\$ 24,227)$ \\
\hline Forgery & $\$ 5,332$ & $7(\$ 37,326)$ & $12(\$ 63,988)$ \\
\hline Theft & $\$ 3,892$ & $6(\$ 23,352)$ & $10(\$ 38,920)$ \\
\hline Driving while intoxicated & $\$ 1,052$ & $27(\$ 28,404)$ & $41(\$ 43,132)$ \\
\hline Drug offense & $\$ 1,052$ & $17(\$ 17,884)$ & $37(\$ 38,924)$ \\
\hline Driving after cancellation & $\$ 1,052$ & $9(\$ 9,468)$ & $23(\$ 24,196)$ \\
\hline $\begin{array}{c}\text { Failure to Register as Predatory } \\
\text { Offender }\end{array}$ & $\$ 1,052$ & $3(\$ 3,156)$ & $4(\$ 4,208)$ \\
\hline Escape/Flee Police & $\$ 1,052$ & $3(\$ 3,156)$ & $7(\$ 7,364)$ \\
\hline False Information to Police & $\$ 1,052$ & $4(\$ 4,208)$ & $4(\$ 4,208)$ \\
\hline Weapon Possession & $\$ 1,052$ & $3(\$ 3,156)$ & $1(\$ 1,052)$ \\
\hline Obstruct Legal Process & $\$ 1,052$ & $2(\$ 2,104)$ & $1(\$ 1,052)$ \\
\hline Other & $\$ 1,052$ & $1(\$ 1,052)$ & $3(\$ 3,156)$ \\
\hline Total & & 134 (\$14.6 million) & 260 (\$17.5 million) \\
\hline Reoffense Costs Avoided & & $-126(-\$ 2.9$ million $)$ & \\
\hline
\end{tabular}

The measure used in this table is the total number of arrests for offenders in both groups; some offenders had multiple rearrests during the follow-up period.

$\$ 109,000$ compared to nearly $\$ 67,000$ for offenders in the comparison group. Overall, the total reoffense costs for InnerChange participants were $\$ 14.6$ million compared to $\$ 17.5$ million for the comparison group. As a result, the total reoffense costs avoided was more than $\$ 2.9$ million, which amounts to $\$ 8,022$ per participant.

As shown in Table 4, InnerChange did not produce a cost avoidance when we examined revocation costs. The 366 InnerChange participants had a total of 190 revocations during the follow-up period, and the average length of stay was 152 days. The 366 comparison group offenders had 192 revocations, but the average length of stay was 142 days. Therefore, InnerChange participants spent 1,735 more days in prison for technical violation revocations during the follow-up period. With an average marginal per diem of $\$ 57$ from 2004-2010, InnerChange produced $\$ 98,895$ in revocation costs.
As noted above, InnerChange participants earned about \$3.7 million more than the comparison group during the follow-up period. The average annual income for the employed offenders was $\$ 12,181$. According to Minnesota tax tables, individuals earning $\$ 12,181 /$ year would have paid $\$ 646$ each year to the State of Minnesota, or 5.3 percent of their annual income. Therefore, it is expected that InnerChange participants paid $\$ 197,216$ to the State of Minnesota in excess of what the comparison group was able to contribute (i.e., 5.3 percent of $\$ 7,987,888$ ).

Overall, InnerChange generated an estimated recidivism benefit of more than $\$ 2.8$ million after we subtract the revocation cost $(\$ 98,895)$ from the reoffense benefit $(\$ 2,936,018)$. After adding the nearly $\$ 200,000$ in state income tax benefits, the results show InnerChange has produced a total estimated benefit of $\$ 3,034,339$ during its first six years of operation. 
Dividing the total benefits by number of participants yields an estimated benefit of $\$ 8,291$ per participant.

Table 4: InnerChange Recidivism and Employment Cost Avoidance Results

\begin{tabular}{|c|c|}
\hline Recidivism & \\
\hline \multicolumn{2}{|l|}{ Reoffense Costs } \\
\hline InnerChange (134 reconvictions) & $\$ 14,607,742$ \\
\hline Average Per Conviction & $\$ 109,013$ \\
\hline Comparison Group (260 reconvictions) & $\$ 17,543,760$ \\
\hline Average Per Conviction & $\$ 67,476$ \\
\hline Total Reoffense Costs Avoided & $\$ 2,936,018$ \\
\hline Reoffense Costs Avoided Per Participant & $\$ 8,022$ \\
\hline \multicolumn{2}{|l|}{ Revocation Costs } \\
\hline InnerChange (190 revocations) & 28,842 days \\
\hline Average \# Days Per Revocation & 152 days \\
\hline Revocation Costs ( $\$ 57 /$ day) & $\$ 1,643,994$ \\
\hline Comparison Group (192 revocations) & 27,107 days \\
\hline Average \# Days Per Revocation & 142 days \\
\hline Revocation Costs ( $\$ 57 /$ day) & $\$ 1,545,099$ \\
\hline Total Revocation Costs & $(\$ 98,895)$ \\
\hline Revocation Costs Per Participant & $(\$ 270)$ \\
\hline \multicolumn{2}{|l|}{ Post-Release Employment Costs } \\
\hline \multicolumn{2}{|l|}{ Total Wages Earned } \\
\hline InnerChange & $\$ 11,708,937$ \\
\hline Comparison & $\$ 7,987,888$ \\
\hline Difference & $\$ 3,721,049$ \\
\hline State Income Tax (5.3\% rate) & $\$ 197,216$ \\
\hline Per Participant & $\$ 539$ \\
\hline \multicolumn{2}{|l|}{ Total Cost-Benefit Results } \\
\hline Program Costs to State & $\$ 0$ \\
\hline \multicolumn{2}{|l|}{ Benefits } \\
\hline Recidivism & $\$ 2,837,123$ \\
\hline Reoffending & $\$ 2,936,018$ \\
\hline Technical Violation Revocations & $(\$ 98,895)$ \\
\hline Employment/State Income Tax & $\$ 197,216$ \\
\hline Total InnerChange Benefits & $\$ 3,034,339$ \\
\hline Benefit per Participant & $\$ 8,291$ \\
\hline
\end{tabular}

To place the InnerChange benefit per participant results within a broader context, it is worth considering the study by Aos, Miller and Drake (2006) on the cost effectiveness of correctional programs. In their study, Aos et al. (2006) identified ten programs for adult offenders that produced a monetary benefit, which ranged from $\$ 870$ to $\$ 13,738$ per participant. With an estimated benefit of $\$ 8,291$ per participant, InnerChange would fall in the middle of the pack among the ten cost-effective correctional programs identified by Aos et al. (2006). Adjusting the Aos et al. (2006) estimates for inflation, the benefit per participant value for InnerChange most closely resembles that for prison-based drug treatment ( $\$ 8,475$ in 2010 dollars).

\section{CONCLUSION}

Research is beginning to help us understand the importance of religion not only as a protective factor, but as one promoting beneficial and prosocial outcomes. This beneficial relationship is not simply a function of religion's constraining function or what it discourages-opposing drug use or violent behaviorbut also through what it encourages-promoting purposive and law-abiding behavior. And yet, religion measures are not routinely included in research examining important social outcomes. The current study is an example of the need for new research, especially drawing upon the field of economics, which will help us more fully understand and gauge the ways in which religion may directly or indirectly impact crime and recidivism, as well as various prosocial outcomes. Unraveling the role of religiosity, religious institutions and congregations, as well as religious practices and beliefs, in promoting prosocial behavior should be a priority for academic researchers as well as federal and private sources of funding.

As policy makers consider cost-effective strategies to reduce delinquency, gang activity, and crime, it is essential for such deliberations to seriously and intentionally consider the potential role of faithmotivated groups in implementing, developing, and sustaining multifaceted approaches. Many faith-based organizations will never seek government funding for the delivery of social services. This is a decision that should be fully respected. However, many other faithbased groups, especially those located in some of our most disadvantaged communities, are ready and willing to work with the government and secular groups in playing a more central role in combating any number of social ills. In a time of economic hardship, it would seem prudent for secular and sacred groups to consider working together in order to develop evidence-based approaches to confront social problems like offender rehabilitation and prisoner reentry. It is increasingly apparent that any strategy to target such areas will be needlessly incomplete unless 
the power of religion and religious communities are integrally involved.

\section{REFERENCES}

Albrecht, Stan, Bruce Chadwick, and David Alcorn. 1977. "Religiosity and Deviance: Application of an Attitude-behavior Contingent Consistency Model." Journal for the Scientific Study of Religion 16: 263-274. http://dx.doi.org/10.2307/1385697

Aos, Steve, Marisa Miller, and Elizabeth Drake. 2006. Evidencebased Public Policy Options to Reduce Future Prison Construction, Criminal Justice Costs, and Crime Rates. Olympia, WA: Washington State Institute for Public Policy.

Aos, Steve, Polly Phipps, Robert Barnoski, and Roxanne Lieb. 2001. The Comparative Costs and Benefits of Programs to Reduce Crime. Seattle, WA: Washington State Institute for Public Policy.

Baier, Colin J. and Bradley R. E. Wright. 2001. "If You Love Me, Keep My Commandments": A Meta-analysis of the Effect of Religion on Crime. Journal of Research in Crime and Delinquency 38: 3-21. http://dx.doi.org/10.1177/0022427801038001001

Berg, Mark and Beth M. Huebner. 2011. "Reentry and the Ties that Bind: An Examination of Social Ties, Employment, and Recidivism." Justice Quarterly 28: 382-410. http://dx.doi.org/10.1080/07418825.2010.498383

Burkett, Steven and Mervin White. 1974. "Hellfire and Delinquency: Another Look." Journal for the Scientific Study of Religion 13:455-462. http://dx.doi.org/10.2307/1384608

Cohen, Mark A. and Alex R. Piquero. 2009. "New Evidence on the Monetary Value of Saving a High Risk Youth." Journal of Quantitative Criminology 25:25-49. http://dx.doi.org/10.1007/s10940-008-9057-3

Cullen, Francis T. 2002. "Rehabilitation and Treatment Programs." Pp. 253-291 in Crime: Public Policies for Crime Control, edited by James $Q$. Wilson and Joan Petersilia. Oakland, CA: Institute for Contemporary Studies.

Cullen, Francis T. and Paul Gendreau. 2000. "Assessing Correctional Rehabilitation: Policy, Practice, and Prospects." Pp. 109-175 in Policies, Processes, and Decisions of the Criminal Justice System, edited by Julie Horney, John Martin, Doris Layton MacKenzie, Ruth D. Peterson, and Dennis Rosenbaum. Washington, D.C.: National Institute of Justice.

DeLisi, Matt, Anna Kosloski, Molly Sween, Emily Hachmeister, Matt Moore, and Alan Drury. 2010. "Murder by Numbers: Monetary Costs Imposed by a Sample of Homicide Offenders." The Journal of Forensic Psychiatry \& Psychology 21:501-513. http://dx.doi.org/10.1080/14789940903564388

Duwe, Grant. 2010. "Prison-based Chemical Dependency Treatment in Minnesota: An Outcome Evaluation." The Journal of Experimental Criminology 6: 57-81. http://dx.doi.org/10.1007/s11292-010-9090-8

Duwe, Grant and Robin Goldman. 2009. "The Impact of Prisonbased Sex Offender Treatment on Sex Offense Recidivism: Evidence from Minnesota." Sexual Abuse: A Journal of Research and Treatment 21: 279-307.

Duwe, Grant and Deborah Kerschner. 2008. "Removing a Nail from the Boot Camp Coffin: An Outcome Evaluation of Minnesota's Challenge Incarceration Program." Crime \& Delinquency 54: 614-643. http://dx.doi.org/10.1177/0011128707301628

Duwe, Grant and Michelle King. 2013. "Can Faith-based Correctional Programs Work? An Outcome Evaluation of the InnerChange Freedom Initiative in Minnesota." International Journal of
Offender Therapy and Comparative Criminology 57: 813841.

http://dx.doi.org/10.1177/0306624X12439397

Evans, David, Francis Cullen, Velmer S. Burton, Jr., R. Gregory Dunaway, Gary L. Payne, and Sesha R. Kethineni. 1996. "Religion, Social Bonds, and Delinquency," Deviant Behavior 17: $43-70$

http://dx.doi.org/10.1080/01639625.1996.9968014

Freeman, Richard B. 1986. "Who Escapes? The Relation of Churchgoing and Other Background Factors to the Socioeconomic Performance of Black Male Youths from Inner-city Tracts." Pp. 353-376 in The Black Youth Employment Crisis, edited by Richard B. Freeman and Harry J. Holzer. Chicago, IL: University of Chicago Press.

Gaes, Gerald, Timothy J. Flanagan, Lawrence Motiuk, and Lynn Stewart. 1999. "Adult Correctional Treatment." Pp. 361-426 in Prisons, edited by Michael Tonry and Joan Petersilia. Chicago, IL: University of Chicago Press.

Granovetter, Mark S. 1983. "The Strength of Weak Ties: A Network Theory Revisited." Sociological Theory 1: 201-233. http://dx.doi.org/10.2307/202051

Higgins, Paul and Gary Albrecht. 1977. "Hellfire and Delinquency Revisited." Social Forces 55: 952-958.

Hirschi, Travis and Rodney Stark. 1969. "Hellfire and Delinquency." Social Problems 17: 202-213 http://dx.doi.org/10.2307/799866

Jensen, Gary F. and Maynard L. Erickson. 1979. "The Religious Factor and Delinquency: Another Look at the Hellfire Hypothesis." Pp. 157-177 in The Religious Dimension, edited by Robert Wuthnow. New York: Academic Press.

Johnson, Byron. R. 2001. "The Role African American Churches in Reducing Crime Among Black Youth." Institute for Studies of Religion (ISR Research Report), Baylor University http://www.isreligion.org/publications/reports/.

Johnson, Byron, R. 2004. "Religious Programs and Recidivism among Former Inmates in Prison Fellowship Programs: A Long-Term Follow-Up Study." Justice Quarterly 21: 329-354. http://dx.doi.org/10.1080/07418820400095831

Johnson, Byron R. and Sung Joon Jang. 2010. "Religion and Crime: Assessing the Role of the Faith Factor." Pp. 117-150 in Contemporary Issues in Criminological Theory and Research: The Role of Social Institutions, edited by Richard Rosenfield, Kenna Quinet, and Crystal A. Garcia. Belmont, CA: Wadsworth.

Johnson, Byron R. and David B. Larson. 2003. "The InnerChange Freedom Initiative: A Preliminary Evaluation of a Faith-based Prison Program." Philadelphia, PA: Center for Research on Religion and Urban Civil Society.

Johnson, Byron R. and Marc V. Siegel. 2008. "The Great Escape: How Religion Alters The Delinquent Behavior of High-Risk Adolescents." ISR Report, Institute for Studies of Religion, Baylor University, 2008 (http://www.isreligion.org/pdf/ISR_ Great_Escape.pdf).

Johnson, Byron R. and David B. Larson and Timothy G. Pitts. 1997. "Religious Programs, Institutional Adjustment, and Recidivism Among Former Inmates in Prison Fellowship Programs." Justice Quarterly 14: 145-166. http://dx.doi.org/10.1080/07418829700093251

Johnson, Byron R., Spencer De Li, David B. Larson, and Michae McCullough. 2000. Religion and Delinquency: A Systematic Review of the Literature. Journal of Contemporary Criminal Justice 16: 32-52. http://dx.doi.org/10.1177/1043986200016001003

Johnson, Byron R., Ralph Brett Tompkins, and Derek Webb. 2002. "Objective Hope - Assessing the Effectiveness of Faithbased Organizations: A Review of the Literature." ISR Report, Baylor University (www.isreligion.org/pdf/ISR Objective_Hope.pdf). 
Johnson, Byron R., David B. Larson, Sung Joon Jang, and Spencer De Li. 2000. "The 'Invisible Institution' and Black Youth Crime: The Church as an Agency of Local Social Control," Journal of Youth and Adolescence 29: 479-498. http://dx.doi.org/10.1023/A:1005114610839

Johnson, Byron R., David B. Larson, Spencer De Li, and Sung Joon Jang. 2000. "Escaping from the Crime of Inner Cities: Church Attendance and Religious Salience Among Disadvantaged Youth." Justice Quarterly 17: 377-391. http://dx.doi.org/10.1080/07418820000096371

Lawrence, Sarah, Daniel P. Mears, Glenn Dublin, and Jeremy Travis. 2002. The Practice and Promise of Prison Programming. Washington, DC: Urban Institute.

MacKenzie, Doris L. and Laura J. Hickman. 1998. What Works in Corrections? An Examination of the Effectiveness of the Type of Rehabilitation Programs Offered by Washington State Department of Corrections. College Park: University of Maryland.

Martinson, Robert. 1974. "What Works? Questions and Answers about Prison Reform." Public Interest 35: 22-35.

McCollister, Kathryn, .E., Michael T. French, and Hai Fang. 2010. The Cost of Crime to Society: New Crime-specific Estimates for Policy and Program Evaluation. Drug and Alcohol Dependence 108: 98-109. http://dx.doi.org/10.1016/j.drugalcdep.2009.12.002
Morris, Norval and David J. Rothman. 1998. The Oxford History of the Prison: The Practice of Punishment in Western Society. New York: Oxford University Press.

Pager, Devah. 2003. The Mark of a Criminal Record. The American Journal of Sociology 108: 937-975. http://dx.doi.org/10.1086/374403

Petersilia, Joan. 2003. When Prisoners Come Home: Parole and Prisoner Reentry. New York, NY: Oxford University Press.

Sherman, Lawrence W., Denise Gottfredson, Doris MacKenzie, John Eck, Peter Reuter and Shawn Bushway. 1997. Preventing Crime: What Works, What Doesn't, What's Promising: A Report to the United States Congress. Washington, DC: National Institute of Justice.

Stark, Rodney. 1996. "Religion as Context: Hellfire and Delinquency One More Time." Sociology of Religion 57: 163-173. http://dx.doi.org/10.2307/3711948

Stark, Rodney, Lori Kent, and Daniel Doyle. 1982. "Religion and Delinquency: The Ecology of a Lost Relationship." Journal of Research in Crime and Delinquency 19:4-24. http://dx.doi.org/10.1177/002242788201900102

Western, Bruce, Jeffery R. Kling, and David F. Weiman. 2001. The Labor Market Consequences of Incarceration. Crime \& Delinquency 47: 410-427. http://dx.doi.org/10.1177/0011128701047003007

\section{DOI: http://dx.doi.org/10.6000/1929-4409.2013.02.22}

(C) 2013 Duwe and Johnson; Licensee Lifescience Global.

This is an open access article licensed under the terms of the Creative Commons Attribution Non-Commercial License (http://creativecommons.org/licenses/by-nc/3.0/) which permits unrestricted, non-commercial use, distribution and reproduction in any medium, provided the work is properly cited. 